\title{
A systemic approach to mapping participation with energy transitions
}

DOI:

10.1038/s41560-020-00762-w

Document Version

Accepted author manuscript

Link to publication record in Manchester Research Explorer

\section{Citation for published version (APA):}

Chilvers, J., Bellamy, R., Pallett, H., \& Hargreaves, T. (2021). A systemic approach to mapping participation with energy transitions. Nature Energy, 6, 250-259. https://doi.org/10.1038/s41560-020-00762-w

\section{Published in:}

Nature Energy

\section{Citing this paper}

Please note that where the full-text provided on Manchester Research Explorer is the Author Accepted Manuscript or Proof version this may differ from the final Published version. If citing, it is advised that you check and use the publisher's definitive version.

\section{General rights}

Copyright and moral rights for the publications made accessible in the Research Explorer are retained by the authors and/or other copyright owners and it is a condition of accessing publications that users recognise and abide by the legal requirements associated with these rights.

\section{Takedown policy}

If you believe that this document breaches copyright please refer to the University of Manchester's Takedown Procedures [http://man.ac.uk/04Y6Bo] or contact uml.scholarlycommunications@manchester.ac.uk providing relevant details, so we can investigate your claim.

\section{OPEN ACCESS}




\title{
A systemic approach to mapping participation with energy transitions
}

Chilvers, J. ${ }^{a^{*}}$, Bellamy, R. ${ }^{b}$, Pallett, H. ${ }^{a}$ \& Hargreaves, T. ${ }^{a}$

a Science, Society \& Sustainability (3S) Research Group, School of Environmental Sciences, University of East Anglia, UK.

${ }^{\mathrm{b}}$ Department of Geography, University of Manchester, UK

* Corresponding author. Address: School of Environmental Sciences, University of East Anglia, Norwich Research Park, Norwich, NR4 7TJ, UK. Email: jason.chilvers@uea.ac.uk

\begin{abstract}
Low-carbon transitions demand long-term systemic transformations and meaningful societal engagement. Most approaches to engaging society with energy and climate change fail to address the systemic nature of this challenge, focusing on discrete forms of participation in specific parts of wider systems. Our systemic approach combines comparative case mapping of diverse public engagements across energy systems with participatory Distributed Deliberative Mapping of energy system futures. We show how UK public participation with energy is more diverse than dominant approaches posit. Attending to these more varied models of participation opens up citizen and expert views, values and visions of sustainable energy transitions, revealing support for more distributed energy system futures that recognise the roles of society. Going beyond narrow, discrete understandings of communication and public engagement towards systemic approaches to mapping participation can provide plural and robust forms of social intelligence needed to govern low-carbon transitions in more socially responsive, just and responsible ways.
\end{abstract}

Transitioning to more sustainable and low-carbon energy systems has become a defining challenge of the early $21^{\text {st }}$ century. Keeping increases in global average temperature to well below $2^{\circ} \mathrm{C}$ as set out in the Paris COP21 climate agreement, while ensuring secure and equitable energy services, demands transforming energy systems on unprecedented scales. Many countries around the world have embarked on concerted programmes to steer such change, through a relative focus on technological, infrastructural and economic interventions ${ }^{1}$. It is increasingly recognised, however, that low-carbon transitions also depend on the meaningful engagement of society. ${ }^{2}$ Societal engagement is varyingly seen as crucial to raising public awareness, exploring public support for low- 
carbon policies and technologies ${ }^{3}$, shifting energy-related behaviours and consumption practices ${ }^{4}$, through to underpinning deeper forms of citizenship and democratic accountability in governing energy transitions ${ }^{5}$.

Programmes to engage society in industrialised nations and globally over the past two decades have seen some successes, but have not achieved desired breakthroughs in energy behaviour change (averaging at $7.4 \%$ reductions in energy use ${ }^{6}$ ), in public support for controversial low-carbon energy technologies, or in institutional responsiveness to public values and equity issues ${ }^{7}$. A significant reason for this is that most mainstream approaches to public participation and engagement with energy and climate change insufficiently address the systemic nature of the challenge. Existing approaches are compartmentalised, focus on discrete forms of engagement in specific parts of wider energy systems, and tend to prescribe narrow meanings and metrics of success. For example, behaviour change studies focus on energy consumption and demand in everyday life; attitude surveys and deliberative processes tend to focus on public acceptability of new technologies and policies; whereas community energy initiatives engage citizens in becoming local producers of renewable energy. ${ }^{8}$ Through adopting narrow, discrete and highly partial perspectives on participation, many existing approaches thus fail to capture the diverse, multiple and interconnected ways in which publics engage with energy systems on an ongoing basis. ${ }^{8}$

Recent advances in social science theories and methods question this evident fragmentation and offer novel solutions. First, social theories and methods pertaining to public participation and engagement are undergoing a systemic turn. Recent conceptual developments in deliberative democracy ${ }^{9}$, practice theory ${ }^{10,11}$, and science and technology studies (STS $)^{12,13}$ are shifting from a mainstream view of public engagement as occurring in discrete isolated processes to develop a broader perspective on how diverse forms of participation interrelate and connect up across wider systems. Second, such work shows public engagements to be both diverse and socially constructed. What people and groups in society think and do about complex issues like energy and climate change has been shown to be powerfully shaped by the particular socio-material settings and practices through which they engage, how they are organized, and by whom. ${ }^{8,14,15,16,17}$ Furthermore, these settings and forms of participation are rapidly multiplying as people become more connected with energy systems through distributed forms of energy generation, energy demand response, the rise of digital and smart energy technologies, and so on. Understanding societal engagement with energy transitions in the current era therefore needs to broaden out to 
map diverse engagements across wider systems, and open up to how different models and practices of participation shape outcomes. ${ }^{12,18}$

Recent research has built on developments in national-scale public engagement processes on particular energy technologies ${ }^{19}$, to elicit public attitudes and values on alternatives for energy system change $\mathrm{e}^{20,21}$. This work has taken an important step in moving to a 'whole systems' perspective, identifying public values that should guide future energy system transitions. ${ }^{22}$ However, while opinion surveys and small-group deliberative events allow selected invited public views on energy system transformations to be elicited, they each constitute a discrete, particular and highly formalised model and setting of participation which shapes outcomes. This particular 'whole system' approach to public involvement thus does not directly attend to or capture the wider system of engagements - i.e. the diverse, ongoing, already existing practices and settings through which publics are engaging with, valuing, imagining and acting on energy system transitions in different ways.

In this article we present a systemic approach which seeks to do this, serving as a complement to these recent developments by building on the aforementioned advances in social science theories and methods. It is comprised of two combined mapping methods that we have developed to: map broader diversities of already existing public engagements across energy systems; and on the basis of this open up to these diverse models of participation and energy visions through a distributed deliberative process that engages citizens and specialists in appraising sustainable energy futures.

\section{Mapping public participation across energy systems}

New methods are emerging that can assist with mapping the increasing multiplicity of public participation and citizen engagements across energy systems, including digital methods ${ }^{23}$ through to forms of meta-analysis and comparative case analysis. ${ }^{8}$ The first part of our systemic approach draws on these methods in addition to a systematic review methodology developed by the UK Energy Research Centre (UKERC). ${ }^{24}$ Our comparative case mapping method was developed and applied in a study which produced a comprehensive dataset of 258 cases of UK public participation and engagement with energy occurring between 2010-2015 (see Methods). Opening up to diverse practices of participation according to the aforementioned systemic and practice-based theories meant that these cases and their documentation spanned academic and non-academic settings, as further explained in Methods. 
This mapping across a whole national energy system has shown how forms of public participation and engagement with energy transitions are highly varied and diverse in terms of who participates (not limited to general aggregate populations, consumers, users, activists, communities, active citizens, householders), what they participate in (ranging from everyday engagements with energy efficiency and smart technologies in the home through to larger scale technologies like renewables, hydraulic fracturing and nuclear power) and how they participate (spanning formal surveys, consultations and deliberative processes to forms of protest, digital engagement and everyday practices). ${ }^{25,26}$ Furthermore, analysis has demonstrated how these seemingly disparate engagements do not occur in isolation, as implied by many existing theories and methods. Rather they continually interrelate and shape each other as part of wider 'ecologies of participation' across energy systems. ${ }^{25}$

In this article we move beyond considering these methodological and empirical developments in their own right, to show how our comparative case method for mapping participation and tools like it can work in conjunction with and shape the design of new engagement processes as part of a systemic framework for public participation in national energy transitions. To this end, Figure 1 presents the results of a new synthetic analysis of our comparative case mapping dataset in the form of a heuristic mapping space. We suggest this can be used to inform the design and analysis of participation practices from a systemic perspective, as we demonstrate with the second part of our systemic approach below.

Synthetic coding analysis of the mapping dataset (see Methods) revealed two key axes along which models of participation vary in Figure 1. The first centers on who orchestrates participation ${ }^{8,17}$, ranging from more institution-led or centralized to more citizen-led or distributed participation practices (otherwise termed 'invited' to 'uninvited' public engagement ${ }^{27}$ ). The second axis spans from participation practices that emphasize the expression of views about energy-related issues (discursive commitments) through to those that are more action-oriented (foregrounding material commitments and change). ${ }^{14,28}$ It is important to note that these axes are not binary or absolute distinctions but rather are continua along which forms of participation vary, are hybrid and coproduced. ${ }^{8,29}$ Figure 1 thus offers a heuristic to map different qualities of public participation and engagement across systems, notably the models and practices of participation, who orchestrates and frames the process, and what gets produced. 
Some of the most prevalent models of participation and engagement identified in the comparative case mapping are situated on the left-hand side of Figure 1, including public opinion surveys $(n=41)$, consultations ( $n=23)$, deliberative and public dialogue processes $(n=35)$ that elicit public views on energy issues (in the top-left part of Figure 1), and behavior change initiatives ( $n=50)$ inclusive of consumer engagement and smart meter trials, which emphasize citizen-consumer actions (in the bottom-left part of Figure 1). This reflects an emphasis on invited institution-led public engagement by government, business or scientific organisations across the UK energy system. While not exclusively so, cases in these parts of the map are most often framed in terms of public acceptability of policies and technologies as well as behavior change. ${ }^{30}$

What is particularly striking when visualising the mapping data in Figure 1 is the way it broadens out beyond institution-led public involvement to more citizen-led and grassroots forms of engagement and action. In the top-right part of Figure 1 this includes citizen-led models of public involvement in debating energy issues, which are fewer in number but tend to develop alternative visions of energy futures and challenge existing policies through forms of activism and protest $(n=16)$ and arts-based engagement $(n=9)$. Citizen-led forms of engagement that are more action-oriented appear in the bottom-right part of Figure 1, including more 'bottom-up' grassroots citizen action in community energy and energy co-operatives ( $n=33)$, energy justice groups $(n=2)$ and makerspaces $(n=1)$. Figure 1 also highlights newly emerging practices of participation and forms of engagement which blur distinctions on the two axes, including digital engagement $(n=6)$, sentiment mapping $(n=4)$, codesign ( $n=12$ ), living labs $(n=1)$, and increasing recognition of everyday practices as a mode of engagement $(n=14)$. It is important to note that the models of participation presented in Figure 1 are not absolute and can overlap and transform over time (one example being where a more issueoriented fracking protest morphed and transformed into a more action-oriented community energy initiative). ${ }^{25}$

The analysis presented in Figure 1 provides evidence to support the aforementioned conceptual relationship between the settings and practices of participation, how they are organized, and by whom, in shaping what gets produced. Our analysis shows that broadening out to a wider diversity of citizen-led engagements can identify and reveal additional public perspectives, visions and concerns likely to be missed by instances of participation located on the left-hand side of Figure 1. This was evident across many issues in the mapping dataset, including smart technologies, renewables and hydraulic fracturing (fracking). To illustrate this using the latter example, cases in the comparative case mapping located in the top-left part of Figure 1 - including public opinion 
surveys and deliberative processes (Cases 5 and 11, Supplementary Table 1) - were framed in terms of risks and impacts from fracking to the environment and health, and how impacted communities might be best engaged and compensated. Cases situated in the top-right part of Figure 1 - ranging from media discourses through to forms of activism and protest (Cases 2, 22 and 25, Supplementary Table 1) - revealed additional public concerns over equity, the broader direction of energy transitions, the underlying purposes of fracking, and who stands to benefit and bear the risks (see also ${ }^{31}$ ). Our mapping thus further confirms the findings of earlier research, which shows citizen-led and 'uninvited' forms of participation to often include alternative and more radical visions of energy system change, placing greater emphasis on socio-cultural change as well as alternative models of growth and social progress. ${ }^{5,8}$

This shows that broadening out to map across wider systems of participation can provide additional social intelligence about public values and concerns that may generate resistance to, or suggest alternative, low-carbon energy transitions. Our comparative case mapping has also identified emergent models of participation and citizen action that may lie beyond incumbent institutional framings which, once revealed, can be recognized and further catalyzed through policy interventions to assist low-carbon transitions. Such mappings can complement and add to existing engagement approaches by providing more systemic and plural evidence to inform energy governance and innovation processes. They can also inform and shape the development of new distributed practices of public participation across energy systems, as demonstrated by the second part of our systemic approach.

\section{Distributed deliberative mapping of energy futures}

Mapping existing and past systems of public participation with energy transitions does not replace the need to create new spaces of participation that can imagine, appraise and anticipate alternative energy system futures. Existing social scientific models of engagement for eliciting public views on energy system transitions are firmly located in the top-left part of Figure 1, most often taking the form of professionally facilitated institutionally-framed small-group deliberative exercises or largerscale public surveys. ${ }^{20,32,33}$ While some of these processes have been reflexive about the framing of issues and energy futures under discussion (see for example ${ }^{21}$ ), such thinking has not yet extended to the models of participation employed, which have remained relatively fixed (although for important exceptions see $\left.{ }^{12,16,34}\right)$. The aforementioned advances in social science theories and comparative case mapping results demonstrate how the specific model of participation - i.e. the 
settings and practices through which citizens engage, how they are formatted, and by whom - plays a fundamental role in shaping public views and actions on energy futures. To account for this, in the second part of our systemic approach we undertook a distributed deliberative process that opened up to and actively experimented with varying models of participation as identified across the mapping space in Figure 1.

Deliberative Mapping (DM) is an established participatory multi-criteria appraisal method ${ }^{35}$ which has been successfully applied in appraising future courses of action on complex, uncertain and contentious issues such as radioactive waste management ${ }^{36}$, climate change ${ }^{37}$, medical health technologies ${ }^{38}$ and GM crops $^{39}$. DM symmetrically involves citizens and specialists in: framing the issue or problem; considering alternative courses of action (options) for addressing it; developing criteria by which to appraise the options; assessing the performance of the options against the criteria under optimistic and pessimistic assumptions; and weighing the criteria in terms of relative importance (see Methods). The established DM method seeks to open up the range of actors and perspectives involved by including representative groups of citizens as well as specialists (the latter from academic, government, business and NGO sectors) in small-group deliberative workshops. ${ }^{35}$ DM is particularly suited to exploring future energy system change as it seeks to open up issue framings, alternative visions and provides plural and conditional outputs on the performance of contending transition pathways. ${ }^{40}$

The established DM method adopts a deliberative model of participation, grounded in Habermasian discursive ethics based on equality of inclusion and participant expression mediated by a professional facilitator. ${ }^{35,41}$ In the current study we undertook a DM process on sustainable energy futures in the UK based on this established format involving a lay citizen group and a specialist group, but went further in opening the DM approach up to alternative models of participation identified in the first comparative case mapping part of our systemic approach (see Methods for further details). We call this further development of the DM method 'Distributed Deliberative Mapping' (DDM). Whereas the established deliberative model of DM is situated in the top-left part of Figure 1, we enabled DM to also be undertaken in three already existing groups, organised according to alternative models of participation, associated with the other three quadrants of Figure 1.

These additional settings of participation in the DDM process included: a smart energy trial according to a market research model of participation involving participants as consumers (bottom- 
left part of Figure 1); an activist group campaigning on energy and climate change issues who ascribed to a more autonomous and non-hierarchical model of participation (top-right part of Figure 1), and a community low-carbon innovation group closely associated with a grassroots innovation model of participation and community development (bottom-right part of Figure 1). The participants in the activist and grassroots community settings took a lead in designing and facilitating their own DDM process, according to their established model of participation and in keeping with their citizenled position in Figure 1. It is important to note that the selection of these groups did not seek to achieve geographic representation across different regions of the UK. In keeping with the aforementioned conceptual basis of our systemic approach, they were selected to be reflective of the different models of participation evident across the UK as identified in the first comparative case mapping part, which in itself achieved national coverage (see Methods and Supplementary Figure 1).

DM is flexible in allowing all participants to develop their own options, criteria, option performance scores and weightings. ${ }^{35}$ As a starting point for discussion a broad framing of 'sustainable energy futures in the UK' was formed and the six diverse visions (options) summarised in Table 1 were developed and provided to participants based on existing visions of UK energy system transitions, namely: (1) Business as usual; (2) Large-scale technologies; (3) Deliberative energy society; (4) Smart tech society; (5) Local energy partnerships; and (6) Off-grid communities (see Supplementary Figure 2 for a more detailed version of these energy visions, shown in the format presented to participants). These visions were explicitly socio-technical, opening up beyond technical aspects to encompass alternative social dimensions and futures (including governance arrangements, equity, and models of growth) which are often excluded from technical and participatory appraisals of energy system change. ${ }^{2,42}$

Each of the five groups (total $n=41$ ) engaged in all five steps of the DM process (see Methods). Participants first explored the problem of sustainable energy futures before discussing the visions and in some groups adding their own self-defined visions. The groups then developed criteria to judge the performance of the different energy visions. They then appraised the visions against the criteria where individual participants gave two scores for each vision under each criterion (to reflect vision performance under optimistic and pessimistic assumptions). Finally, participants in each group weighted their criteria in terms of relative importance. The appraisal scores, criteria and their weighting for each participant and DDM group was subject to Multi-criteria Mapping analysis (see Methods) producing overall maps of vision performance for each group as shown in Figure 2. In addition to this quantitative analysis, the reasonings behind these appraisals produced a wealth of 
qualitative data. Table 2 provides select example quotations pertaining to the appraisal of energy visions by the different DDM groups, organised by the main appraisal criteria themes (see Supplementary Table 2 for additional representative quotations).

DDM appraisal maps (Figure 2) show distinctive vision rankings and patterns of internal ambiguity, although broader patterns of vision performance are evident across all groups. In terms of the six core visions appraised the mean rank order across the five groups reveals three tiers of overall core vision performance. The two lowest ranking visions were Business as usual (ranked lowest by deliberative citizens, consumer citizens and specialists, second lowest by activist citizens and fifth lowest by grassroots innovator citizens, e.g. Quotes A, F, G, K, P, Y, EE in Table 2) and Large-scale technologies (ranked lowest by activist citizens and second lowest by consumer citizens, e.g. Quotes $B, H, M, Q, T, Z, F F$ in Table 2). A strong finding from across most DDM groups is the urgent need to shift away from the incumbent energy system (e.g. Quotes A, F, G, K in Table 2), coupled with concern amongst some groups over a reliance on techno-fixes and technologies like bioenergy with carbon capture and storage, nuclear, and advanced biofuels (e.g. Quotes $B, H, Q, T$ in Table 2).

The two middle ranking visions (Figure 2) were Deliberative energy society (ranked second highest out of core options by specialists but lowest by grassroots innovator citizens, e.g. Quotes I, L, U, AA, BB, GG in Table 2) and Off-grid energy communities (ranked highest out of core options by activist citizens and second highest by deliberative citizens but second lowest by grassroots innovator citizens and specialists, e.g. Quotes $\mathrm{E}, \mathrm{J}, \mathrm{O}, \mathrm{X}, \mathrm{DD}$, II in Table 2). The two highest ranking visions were smart-tech society (ranked highest out of core options by grassroots innovator citizens, consumer citizens and specialists, but second lowest by deliberative citizens e.g. Quotes $C, J, M, R, V, C C$ in Table 2) and Local energy partnerships (ranked highest by deliberative citizens and second highest out of core options by activist citizens and consumer citizens, e.g. Quotes D, N, S, W, HH in Table 2). These patterns of option performance across all groups in Figure 2 show expert, policy-maker and public support for a more distributed future energy system that pays greater attention to the roles of society and inclusive modes of governing (e.g. Quotes $D, J, L, N, R, S, W, A A, G G, H H$ in Table 2). The additional visions developed by specialist, activist, grassroots innovator and consumer groups performed highly in comparison to core visions in all cases (Figure $2 \mathrm{a}, \mathrm{c}, \mathrm{d}, \mathrm{e}$ ).

These DDM results provide further evidence that the model of participation, and the formatting of practices through which people participate, plays a crucial role in shaping their perspectives on alternative energy futures. While there are some specific differences in vision rankings, there is consistency between citizen and specialist group appraisals (Figure $2 a, b$ ) in terms of the overall 
pattern of option performance and variability ranges between individual participants. This is especially noteworthy because of the considerable differences in experience and expertise between specialist and lay public participants in these two groups. It suggests very strongly that models of participation matter. The deliberative model and setting of participation in the established DM method was one of the main commonalities between these two groups (see Methods), and thus had a conditioning effect on the appraisal outcomes produced.

Opening up to the consumer, activist and grassroots innovator groups, each with alternative already existing models of participation, created different patterns of vision performance compared to the established DM method (Figure 2, c-e). The variability ranges between optimistic and pessimistic scores are smaller for the most part and differences in vision rankings are more pronounced. Engaging with these three already existing models of participation in DDM introduced a greater diversity of perspectives on vision performance. Each group identified one core vision as the standout highest performing: off-grid energy communities for the activist group, and smart tech society for the grassroots innovation and smart consumer groups.

Opening up beyond the established DM format to alternative models of participation also introduced a greater diversity of criteria by which to judge future energy system transitions, as shown in Table 3 (see also Table 2 and Supplementary Table 2 for representative quotations associated with these criteria and their application in appraising energy visions). Of particular note in this regard is the activist setting, which introduced a wider range of equity and justice-based criteria as well as concerns over public acceptability compared to deliberative and specialist groups, with greater weighting being place on criteria pertaining to social dimensions of energy system transitions. These DDM findings suggest that experimenting with alternative models of participation and democracy should become a key design concern and explanatory variable in processes of public engagement with energy and climate change, rather than something to be held constant at all costs.

\section{Transforming participation for just transitions}

As the world moves into a low-carbon era urgent policy and technological developments are placing increasing strain on established relations between science, politics and society. Under these conditions the governance of low-carbon transitions needs be responsible, inclusive of and responsive to societal values, public concerns and human needs. ${ }^{5}$ This is about more than public acceptance and behaviour change. It is crucial to renewing the social contract between citizens and 
governing institution $\mathrm{s}^{22}$ and accounting for 'the public interest' in ways that address human needs and ensure more equitable energy transitions. ${ }^{7,43}$ Mainstream approaches for eliciting public views, such as surveys and deliberative processes, are of undoubted value, ${ }^{19,20}$ but underplay and can exclude an ever-growing multiplicity of public engagements with energy and climate change, fuelled by the digital revolution, the rise of social media, citizen-led mobilisations, moves to more distributed energy systems, and so on. ${ }^{14,44,45}$

Our approach seeks to attend to this multiplicity while complementing these existing approaches of invited public elicitation. This has been achieved though developing and combining two mapping methods to form a systemic approach to participation and accounting for public values and actions in national energy system transitions. In the first part, our comparative case mapping findings provide conclusive evidence of the increasing diversity of public engagements with energy. Through broadening out to include emerging or excluded models of participation - from digital democracy to everyday social practices, and from citizen-led forms of activism through to grassroots citizen actions - our study demonstrates how systemic mapping approaches can provide more comprehensive evidence on the diversity of public views and reveal excluded or unrecognised spaces of engagement including potential new sources of low-carbon action. Such mappings can thus help reveal exclusions, omissions and uncertainties in evidence about energy publics. Importantly, our systemic mapping approach and heuristic presented in Figure 1 helps to operationalise the idea of public participation with energy and climate change being ongoing and multiple, and not only institutionled but also citizen-led. The significance and relevance of this is further emphasised by the recent and ongoing emergence of diverse climate change engagements ranging from Extinction Rebellion protests, Fridays for Future school strikes, through to Citizens' Assemblies on low carbon futures, all of which can be mapped by the broader framework we have presented in Figure 1.

In the context of imperatives to accelerate the decarbonisation of energy systems this can in turn support more ongoing and responsive systems of governing, where public values and actions are not seen as fixed but in flux and continually emerging. Here a key challenge becomes one of cultivating new forms of institutional reflection and responsiveness ${ }^{30,46}$ to the diverse forms of public value, visions and actions which already exist across energy systems and across cultures. Approaches to mapping participation can form the basis for new engagement architectures, such as observatories that oversee and map on an ongoing basis how publics and societies are engaging with energy and low-carbon transitions at national, international or sub-national scales. ${ }^{47}$ In addition to oversight of technological and policy developments, such observatories can play a vital role in translating this 
social intelligence to help ensure innovations, policies and engagement practices that seek decarbonisation are also responsible, just and sustainable in the longer-term (for similar proposals made in the context of gene editing see ${ }^{48,49}$ ).

The formation of novel engagement architectures does not reduce the need to cultivate new forms of participation with energy and climate change. Indeed, as the findings of our DDM study show, systemic mappings can inform and enhance the design of anticipatory public engagement on energy and low-carbon transitions. Opening up an established deliberative multi-criteria appraisal method to alternative models of participation identified in our comparative case mapping (Figure 1), has served to reveal additional societal visions, value-based criteria (Table 3 ) and perspectives on the performance of alternative future pathways for energy system transformation (Figure 2). While the value-based criteria generated are broadly comparable, our DDM results differ from the largely centralised policy focus of other large-scale analyses of public views (e.g. ${ }^{20,22}$ ) to also emphasise more distributed patterns of governance and social transformations in energy system change. Deliberately experimenting with alternative models of participation and modes of orchestration in DDM has provided some of the first evidence in the energy field that the practices and formats of participation matter to how energy futures are appraised. ${ }^{50}$ This highlights the need for future public participation experiments to be reflexive and inclusive not only about issue framings and process participants, but also about how the models and practices of participation are formatted and framed. ${ }^{12,16,45}$

Faced with complex, uncertain and systemic challenges of energy and climate change, opening up participation with energy transitions in this way can reveal important social uncertainties and differences between contending interests, while providing recommendations on areas of commonality. ${ }^{18}$ In this sense the DDM has identified expert, policy-maker and public support for more distributed energy system futures that pay greater attention to the roles of society. In sum then, our systemic approach shows how mapping methods in general - and the mapping of systemwide energy participation coupled with distributed deliberative mapping in particular - can provide more plural and robust forms of social intelligence needed to govern low-carbon transitions in more socially responsive, just and responsible ways. This points to the future potential of such systemic mapping approaches in other national and international settings, in longitudinal analyses, and also beyond the fields of energy and climate change. 


\section{Methods}

\section{A systemic approach to participation}

The systemic approach to participation in sociotechnical transitions presented in this article comprises two interrelated mapping methods. The first, comparative case mapping, is an innovative form of comparative case analysis for mapping diverse forms of participation and public engagement across wider systems. The second, Distributed Deliberative Mapping (DDM), further develops an established participatory multi-criteria method for appraising alternative futures and contending courses of action in addressing complex and uncertain public problems, like low carbon energy transitions. The emphasis of both mapping methods is on 'opening up' to diversity and difference, as well as identifying areas of similarity, with respect to constitutive elements associated with a particular object of attention, like public participation or energy transitions. In both methods the term 'mapping' implies efforts at framing, identifying, arranging and visualising constitutive elements and their relations to one another around an object of analysis. In both instances mapping is a form of knowledgemaking and representation as well as an open-ended research method. For comparative case mapping the object being mapped was the collective practices through which publics participate in energy systems transitions, based on mapping analyses by the research team, database searches, documentary evidence and oversight of an advisory group. Whereas in DDM the mapping object was the performance of different options and future pathways for addressing public problems, in this case sustainable energy transitions, with mapping being conducted through the inclusion of diverse experts, stakeholders and publics. Developing and closely integrating these methods for mapping systems of participation and for participatory mapping of system change for the first time forms our new systemic approach to participation and accounting for public values and actions in national energy system transitions.

\section{Mapping participation - comparative case analysis}

The mapping participation method. The mapping of system-wide energy participation was informed by a systematic review methodology developed by the UK Energy Research Centre. ${ }^{24}$ This methodology draws on the protocols developed in medical systematic reviews to enable a systematic review of the academic literature around a clearly defined topic area. Our approach differed from this in several important ways. First, in order to map diverse forms of participation according to the systemic and practice-based theories set out in the introduction to this article, our mapping included not only academic literature but also relevant reports, news articles and websites in the public domain. As we were aware that the academic literature had clear partialities in coverage of particular kinds of public participation with energy over others, and that the time lags in academic publishing cycles meant that more recent cases might not be included, it was important to be able to include instances of participation which had been documented in other ways. Our criteria for inclusion of cases not from the academic literature were that there needed to be enough documented evidence of the case for it to be possible to analyse the case according to the key categories from our conceptual framework ${ }^{8}$ 
${ }^{25}$ : namely, the who (i.e. participants), the how (i.e. model), and the what (i.e. object) of energy participation. All of the cases collected were (re)analysed using this framework, including academic studies of and instances of engagement encompassed by our framework's open definition of participation (as stated in 'Searching and producing the corpus' below). This leads to the second way in which our mapping participation approach differed from the standard UKERC systematic review methodology. In order to include cases beyond the academic literature, we used Web of Science, Scopus, Google Scholar and Google for our searches so that we found a wider diversity of material. The Web of Science and Scopus searches were exhaustive. Due to the much higher number of results produced by Google Scholar and Google, for these searches the first four pages of results were reviewed and the researcher only proceeded further if relevant cases were still found after four pages. The mapping participation comparative case analysis followed a structured process, informed by aspects of systematic review methodology and a practice-based co-productionist theory of participation ${ }^{12,25}$, comprising the following steps: (i) scoping the framework for analysis and search terms; (ii) expert panel feedback on the approach; (iii) searching and screening of academic and grey literature based on synonyms for the model (how), participants (who), and object (issue) of participation; (iv) documentary analysis of 258 cases; and (v) in-depth case study analysis of a subset of 30 cases.

Searching and producing the corpus. The search terms used to identify relevant papers and other materials were based on the structure of 'UK' + 'energy' + 'public' + 'participation'. However, as the corpus we were building mainly consisted of interpretive qualitative studies it was necessary to use a large number of different synonyms in the searches to pick up on different forms of and approaches to public participation and engagement. For example, synonyms for energy included 'electricity', 'heat', 'transport' and 'biofuels'; synonyms for public included 'user', 'stakeholder', 'consumer' and 'citizen'; synonyms for participation included 'engagement', 'dialogue', 'survey' and 'protest'; and synonyms were used for different parts of the UK. A full list of synonyms can be found in the full technical report of the mapping participation analysis. ${ }^{51}$ The synonyms used were systematically identified through an initial reading of relevant academic literature on energy participation and advice from the project's expert advisory panel during the scoping phase of this process. In order to assess a case's relevance the researcher read each paper, report or website to check if it fitted our study's open definition of energy participation as: 'heterogeneous collective practices through which publics engage in addressing collective public problems (in this case 'energy-related' issues), whether deliberately or tacitly, which actively produces meanings, knowings, doings and/or forms of social organization'. Cases of participation in the corpus achieved national coverage across different regions of the UK (see Supplementary Figure 1).

Comparative case analysis. The final corpus of 258 cases of public participation and engagement with energy (see Supplementary Table 3) was coded by the researcher according to the who, what and how of energy participation in addition to categories such as regions in the UK, the issue domain the case belonged to, methods used, institutional settings and aims. This coding was cross-checked for consistency by the principle investigator of the project. A more fine-grained analysis was conducted on a sub-set of 30 cases (see 
Supplementary Table 1) from the large corpus in order to gain a deeper understanding of diverse cases of participation, their productivities in terms of public views and actions, how they interacted with each other and with the broader energy system. We have reported separately on aspects of this analysis pertaining to the diverse forms of public participation and engagement with energy transitions and how they interact as part of wider ecologies of participation that make up energy systems ${ }^{25,26}$. Instead of reporting on different dimensions (such as the who, what and how) of participation separately, in this article we present a synthetic analysis conducted across the whole dataset and qualitative coding framework. Synthetic coding analysis of the mapping dataset revealed two key axes of difference along which practices of participation vary: (i) who orchestrates the process (ranging from institution-led to citizen-led); and (ii) what is participation for and what gets produced (ranging from the expression of views about energy-related issues through to material commitments and actions). Codes relating to models of participation, who orchestrates and frames the process, and what gets produced in terms of public views and actions, were thus synthesized through interpretive analysis to produce the heuristic mapping space presented in Figure 1, with models of participation plotted in relation to the two axes.

Visualisation. The final stage of the comparative case mapping was to create visualisations of significant trends and patterns observed in the cases studied, the main summary output from which is shown in Figure 1, to help interpret and communicate the patterns of public participation and engagement with energy in the UK occurring between 2010 and 2015. This analysis and the heuristic mapping space presented in Figure 1 informed and shaped the design of the second distributed deliberative mapping part of our systemic approach.

\section{Distributed Deliberative Mapping}

Visions. To generate a diverse set of core visions (or 'options') for all participants to appraise we undertook a review of diverse existing visions and scenarios of future energy transitions for the UK. This captured visions set out by: (i) the UK Government, including those within the Carbon Plan; (ii) business, including those developed by the National Grid; (iii) civil society, including those proposed by Greenpeace; and (iv) academia, including those used in earlier technical and social science research studies by the UK Energy Research Centre. The review identified five primary axes of difference between the visions. These consisted of technical assumptions about how energy would be produced, distributed and used, and social assumptions about growth and governance. In turn, each of these dimensions could be further differentiated. On the technical side, some visions emphasised energy produced by fossil fuels and nuclear power, for instance, while others emphasised renewable energy or more speculative technologies. Some visions assumed a centralised distribution grid run by large energy companies, whereas others assumed a decentralised grid. Similarly, some visions envisaged lowered demand through behavioural changes, whereas others envisaged more energy efficient technologies, improving responsiveness to demand or more radical reductions in usage. On the social 
side, some visions assumed a status quo model of economic growth, while others assumed alternative models of growth that emphasised non-monetary values. In terms of governance, some visions assumed a market regulated by government with little involvement from citizens, whereas others assumed more government investment, less regulation, localised decision making or citizen-led decisions. An attention to the five axes of difference allowed us to then develop six very distinctive and contrasting core visions for appraisal: business as usual; large-scale technologies; deliberative energy society; smart tech society; local energy partnerships; and off-grid energy communities (see Supplementary Figure 2). These were further illustrated by identifying the key actors or proponents and some real-world examples associated with each vision. They were brought together under an overarching framing of 'sustainable energy futures for the UK', with a 2050 time horizon.

Participants. Enrolment of DDM participants was appropriate to each of the five groups involved, comprising one group of specialists and four groups of citizens based on diverse models of participation in the UK energy system, namely: deliberative citizens, activist citizens, grassroots innovator citizens and consumer citizens (see main text). In keeping with the conceptual basis of our practice-based systemic approach to participation (outlined in the Introduction), the selection of these groups foregrounded the models of energy participation evident across the UK as the main entry point and comparative basis for participant sampling. The selection of the four citizen groups was thus based on the findings of the UK-wide participation mapping summarised in Figure 1, where each group of citizens was selected to represent one model of participation from one of the four quadrants of the mapping space. Enrolment of the specialist and deliberative citizen groups followed the established procedure used in conventional Deliberative Mapping, ${ }^{35}$ identifying and inviting diverse senior energy specialists from across government, business, NGOs and academia around the UK $(n=7)$ and selecting a quota of lay citizens reflecting key socio-demographic characteristics of the population of Norfolk $(n=9)$. The lay citizen group was drawn from responses to an online survey administered by the research team through the Norfolk County Council 'Your Voice' citizens panel $(n=118)$, which took account of age, gender and socioeconomic status variables as well as world issues of most concern (such as climate change, world population, poverty or an economic downturn), relationships with energy (such as smart meters, domestic renewables or paying bills) and preferred approach to an energy transition (expert, market or collectively led). The enrolment of the three already existing groups was quite different, involving the identification and invitation of already existing groups in society based on their pre-existing models of engagement and the requirement for them to be active and accessible during the period of study, namely a UK environmental activist group which formed in opposition to a multinational oil and gas company in London ( $n=6)$; a grassroots Mutual Society seeking to innovate and improve energy efficiency and reduce the carbon footprint of its community in Oxfordshire, UK $(n=11)$; and members of a smart energy control technology trial in Wiltshire, UK $(n=8)$.

Procedure. Taking place between January-July 2017, the five groups' appraisals all followed the same established five-step procedure used in conventional DM: issue framing, option creation, criteria development, option scoring and criteria weighting. ${ }^{35}$ In the specialists group, which convened in a half-day 
workshop, the latter four steps were conducted on an individual basis using laptops pre-loaded with Multicriteria Mapping software (www.multicriteriamapping.com). To reflect the groups' differing levels of experience with energy issues and their availability, the specialists group took place over the course of an afternoon, the deliberative citizens group took longer over the course of a full day, and the already existing groups each took place over the course of a morning or evening session. Much like the specialists' group, running the exercise with the already existing citizens groups was shorter owing to their prior engagement with the topic. By contrast, the deliberative citizens group was given an introduction to the topic such that lay expertise was developed. Crucially, however, the procedure in the already existing groups was collaboratively designed over an extended period of weeks prior to the events, with a key representative of the group structuring-and then facilitating - the DM method in keeping with the typical ways in which their groups would organise during their meetings and interactions. While the DDM process was framed overall as an exercise in appraising 'sustainable energy futures for the UK', each group appraisal began with a discussion of what the participants themselves felt the issues facing the energy system were. Moreover, while a set of six diverse core visions were developed by the research team for all participants to appraise (Supplementary Figure 2), each group was also given the opportunity to develop additional, self-defined visions. The way in which criteria were developed differed between the groups. In the conventional DM groups, the specialists developed their criteria individually and the deliberative citizens developed their criteria as a group through a process of negotiated amalgamation, whereby individual criteria were clustered into common themes. The grassroots innovator and consumer citizen groups also opted for a negotiated amalgamation approach to criteria development, while the activist citizens developed theirs instead through collective deliberation. All groups scored the visions in the same way, using the established method-unique to DM-in which individual participants give two scores for each vision under each criterion: one under optimistic assumptions and one under pessimistic assumptions. This produces an uncertainty range for individual participants and allows for the analysis of a variability range across participants (as presented in Figure 2). Finally, with the exception of the activist group which opted to weight all their criteria equally, individuals within each group weighted their criteria in terms of their relative importance (as shown in Table 3). While we had deliberately experimented with the format of DM, and indeed formally recognise this difference by giving it a distinct name (DDM), all of the core components of DM from previous exercises were present, i.e. issue framing, option definition, criteria development, option scoring, criteria weighting and participant review.

Analysis. The DDM process produced a wealth of quantitative and qualitative data, including the quantitative scoring of options and weightings of criteria and the audio-recorded and transcribed participant reasonings that underpinned those scores and weights. The data were analysed in accordance with established methods of DM analysis, including multicriteria mapping analysis and qualitative coding analysis. ${ }^{35}$ Quantitative data relating to the scoring of options, criteria and criteria weightings were subject to multi-criteria analysis using Multi-criteria Mapping software (available at www.multicriteriamapping.com) to produce the energy vision performance maps presented in Figure 2. Qualitative data was subject to qualitative coding analysis to 
establish key themes in the data set, including in relation to participant-derived criteria as presented in Table

2, Table 3 and Supplementary Table 2.

Data availability. Data and documentation for all 258 cases in the mapping participation comparative case analysis can be viewed here (https://docs.google.com/spreadsheets/d/1P2IFFMFBZakZYMOTWAZo9vdwNXOn8TaRj4H4sKJpgQ/edit\#gid=0). Data and material that support the findings of the DDM study are available from the corresponding author upon reasonable request after two years from publication of this article.

\section{References}

1. IPCC. Climate Change 2014: Mitigation of Climate Change. Contribution of Working Group III to the Fifth Assessment Report of the Intergovernmental Panel on Climate Change. CUP: Cambridge 2014.

2. Miller C, Richter J, O'Leary J. Socio-energy systems design: A policy framework for energy transitions. Energy Research \& Social Science 2015, 6: 29-40.

3. Bidwell D. Thinking through participation in renewable energy decisions. Nature Energy 2016, 1: 16051.

4. Shove E, Walker G. What Is Energy For? Social Practice and Energy Demand. Theory Culture \& Society 2014, 31(5): 41-58.

5. Stirling A. Transforming power: Social science and the politics of energy choices. Energy Research \& Social Science 2014, 1: 83-95.

6. Delmas MA, Fischlein M, Asensio OI. Information strategies and energy conservation behavior: A meta-analysis of experimental studies from 1975 to 2012. Energy Policy 2013, 61: 729-739.

7. Jasanoff S. Just transitions: A humble approach to global energy futures. Energy Research \& Social Science 2018, 35: 11-14.

8. Chilvers J, Longhurst N. Participation in Transition(s): Reconceiving Public Engagements in Energy Transitions as Co-Produced, Emergent and Diverse. J Environ Pol Plan 2016, 18(5): 585-607.

9. Parkinson J, Mansbridge J (eds). Deliberative Systems: Deliberative Democracy at the Large Scale. Cambridge University Press: Cambridge, 2012.

10. Watson M. How theories of practice can inform transition to a decarbonised transport system. Journal of Transport Geography 2012, 24: 488-496.

11. Hui A, Schatzki T, Shove E. The Nexus of Practices: Connections, Constellations, Practitioners. Routledge: Abingdon, 2016. 
12. Chilvers J, Kearnes M (eds). Remaking Participation: Science, Environment and Emergent Publics. Routledge: Abingdon, 2016.

13. Braun K, Könninger S. From experiments to ecosystems? Reviewing public participation, scientific governance and the systemic turn. Public Understanding of Science 2017: 0963662517717375.

14. Marres N. Material Participation: Technology, the Environment and Everyday Publics. Palgrave Macmillan: Basingstoke, 2012.

15. Chilvers J, Kearnes M. Remaking participation in science and democracy. Science, Technology, \& Human Values 2020, 45(3): 347-380.

16. Bellamy R, Lezaun J, Palmer J. Public perceptions of geoengineering research governance: An experimental deliberative approach. Global Environmental Change 2017, 45: 194-202.

17. Skjølsvold TM, Throndsen W, Ryghaug M, Fjellså IF, Koksvik GH. Orchestrating households as collectives of participation in the distributed energy transition: New empirical and conceptual insights. Energy Research \& Social Science 2018, 46: 252-261.

18. Stirling A. "Opening up" and "Closing down" - Power, participation, and pluralism in the social appraisal of technology. Science Technology \& Human Values 2008, 33(2): 262-294.

19. Burgess J, Chilvers J. Upping the ante: a conceptual framework for designing and evaluating participatory technology assessments. Science and Public Policy 2006, 33(10): 713-728.

20. Pidgeon N, Demski C, Butler C, Parkhill K, Spence A. Creating a national citizen engagement process for energy policy. P Natl Acad Sci USA 2014, 111 Suppl: 13606-13613.

21. Demski C, Spence A, Pidgeon N. Effects of exemplar scenarios on public preferences for energy futures using the my2050 scenario-building tool. Nature Energy 2017, 2(4): nenergy201727.

22. Demski C, Butler C, Parkhill KA, Spence A, Pidgeon NF. Public values for energy system change. Global Environmental Change 2015, 34: 59-69.

23. Marres N. Digital Sociology: The reinvention of social research. Polity Press: Cambridge, 2017.

24. Sorrell S. Improving the evidence base for energy policy: The role of systematic reviews. Energy Policy 2007, 35(3): 1858-1871.

25. Chilvers J, Pallett $\mathrm{H}$, Hargreaves T. Ecologies of participation in socio-technical change: The case of energy system transitions. Energy Research \& Social Science 2018, 42: 199-210.

26. Pallett $\mathrm{H}$, Chilvers J, Hargreaves T. Mapping participation: A systematic analysis of diverse public participation in the UK energy system. Environment and Planning E 2019, 23(3): 590616. 
27. Wynne B. Public participation in science and technology: performing and obscuring a political-conceptual category mistake. East Asian Science, Technology and Society: An International Journal 2007, 1(1): 99-110.

28. Smith A, Stirling A. Moving outside or inside? Objectification and reflexivity in the governance of socio-technical systems. J Environ Pol Plan 2007, 9(3-4): 351-373.

29. Jasanoff S (ed). States of Knowledge: The Co-production of Science and Social Order. Routledge: Abingdon, 2004.

30. Pallett $\mathrm{H}$, Chilvers J. A decade of learning about publics, participation, and climate change: institutionalising reflexivity? Environment and Planning A 2013, 45(5): 1162-1183.

31. Williams L, Macnaghten P, Davies R, Curtis S. Framing 'fracking': Exploring public perceptions of hydraulic fracturing in the United Kingdom. Public Understanding of Science 2017, 26(1): 89-104.

32. Stagl S. Multicriteria evaluation and public participation: the case of UK energy policy. Land Use Policy 2006, 23(1): 53-62.

33. Hendriks CM. Policy design without democracy? Making democratic sense of transition management. Policy Sciences 2009, 42(4): 341-368.

34. Krzywoszynska A, Matt W, Buckley A, Chiles P, Gregson N, Holmes H, et al. Opening Up the Participation Laboratory: The Cocreation of Publics and Futures in Upstream Participation. Science, Technology, \& Human Values 2017: 0162243917752865.

35. Burgess J, Stirling A, Clark A, Davies G, Eames M, Staley K, et al. Deliberative mapping: a novel analytic-deliberative methodology to support contested science-policy decisions. Public Understandng of Science 2007, 16(3): 299-322.

36. Chilvers J, Burgess J. Power relations: the politics of risk and procedure in nuclear waste governance. Environment and Planning A 2008, 40(8): 1881-1900.

37. Bellamy R, Chilvers J, Vaughan NE. Deliberative Mapping of options for tackling climate change: Citizens and specialists 'open up' appraisal of geoengineering. Public Understanding of Science 2016, 25(3): 269-286.

38. Davies G. The sacred and the profane: biotechnology, rationality, and public debate. Environment and Planning A 2006, 38(3): 423-443.

39. Stirling A, Mayer S. A novel approach to the appraisal of technological risk: a multicriteria mapping study of a genetically modified crop. Environment and Planning C-Government and Policy 2001, 19(4): 529-555.

40. Leach M, Scoones I, Stirling A. Dynamic Sustainabilities: Technology, Environment, Social Justice. Earthscan: London, 2010.

41. Stern P, Fineberg H. Understanding Risk: Informing Decisions in a democratic Society. National Academy Press: Washington DC, 1996. 
42. Chatterton T. Public engagement: Building energy futures. Nature Energy 2017, 2(4): 17030.

43. Macnaghten $\mathrm{P}$, Chilvers J. The future of science governance: publics, policies, practices. Environment and Planning C-Government and Policy 2014, 32(3): 530-548.

44. Walker G, Cass N. Carbon reduction, 'the public' and renewable energy: engaging with sociotechnical configurations. Area 2007, 39(4): 458-469.

45. Chilvers J, Pallett $\mathrm{H}$. Energy democracies and publics in the making: a relational agenda for research and practice. Frontiers in Communication 2018, 3: 14.

46. Wynne B. Public uptake of science: A case for institutional reflexivity. Public Understanding of Science 1993, 2: 321-337.

47. Chilvers J, Pallett $\mathrm{H}$, Hargreaves T. Public engagement with energy: broadening evidence, policy and practice. London: UK Energy Research Centre; 2017.

48. Burall S. Rethink public engagement for gene editing. Nature 2018, 555(7697): 438-439.

49. Jasanoff S, Hurlbut J. A global observatory for gene editing. Nature 2018, 555(7697): 435437.

50. Latour B, Weibel P. Making Things Public: Atmospheres of Democracy. MIT Press: Cambridge, MA, 2005.

51. Pallett $\mathrm{H}$, Chilvers J, Hargreaves T. Mapping energy participation: A systematic review of diverse practices of participation in UK energy transitions, 2010-2015. London: UK Energy Research Centre; 2016.

\section{Acknowledgements}

The research presented in this article was funded by the UK Research Councils as part of the UK Energy Research Centre (UKERC) Phase 3 research programme [EPSRC award EP/L024756/1]. We are grateful to the citizens and specialists who participated in the Distributed Deliberative Mapping study.

\section{Author contributions}

$\mathrm{JC}$ led the research and its overall design as Principle Investigator. The comparative case mapping was led by JC with data collection and analysis being undertaken by HP with inputs from JC and TH. All authors contributed to the design and data collection of the Distributed Deliberative Mapping, with analysis being led by JC and undertaken by RB. JC wrote the article with contributions from RB, $\mathrm{HP}$ and TH.

Competing interests. The authors declare no competing interests. 
Figure 1. A heuristic framework for mapping diversities of public participation across wider systems, based on the results from mapping participation in the UK energy system, 2010-2015 ( $n=258$ cases in total). Models of participation are mapped on two dimensions based on the degree to which they are predominantly (i) institution-led or citizen-led and (ii) involve engagement in issues or actions. Some smaller categories identified in the corpus with low (n) values are not included in the figure, namely: formal political processes $(n=3)$; media discourse $(n=1)$; community participation $(n=1)$; social impacts $(n=3)$; public perceptions research $(n=2)$; and action research $(n=1)$.

Figure 2. Deliberative mappings of energy vision performance as appraised by (a) specialists ( $n=7),(b)$ deliberative citizens ( $n=9),(c)$ activist citizens $(n=6),(d)$ grassroots innovator citizens $(n=11)$ and (e) consumer citizens $(n=8)$. The length of the thick bars represents the mean difference in performance under optimistic and pessimistic assumptions. The length of the error bars represents the extremes (highest and lowest values) in vision performance under optimistic and pessimistic assumptions. The $\mathrm{x}$-axis is a relative scale from 0 (lowest performance) to 100 (highest performance). * indicates additional options developed and appraised by specific groups.

\begin{tabular}{|c|c|}
\hline Future energy vision & Summary description \\
\hline Business as usual & A vision of a future where the energy system is similar to how it is now. \\
\hline Large-scale technologies & $\begin{array}{l}\text { A vision of a future where new technologies are developed and deployed to reduce } \\
\text { carbon dioxide emissions. }\end{array}$ \\
\hline Deliberative energy society & $\begin{array}{l}\text { A vision of a future where the public has much more of a say over what happens with } \\
\text { the energy system. }\end{array}$ \\
\hline Smart tech society & $\begin{array}{l}\text { A vision of a future where 'smart' technologies are used to make the energy system } \\
\text { more connected and efficient. }\end{array}$ \\
\hline Local energy partnerships & $\begin{array}{l}\text { A vision of a future where people work together in partnership for localised energy } \\
\text { systems. }\end{array}$ \\
\hline Off-grid energy communities & A vision of a future where communities live 'off-grid'. \\
\hline
\end{tabular}

Table 1. Six sociotechnical visions of energy system futures appraised by participants in Distributed Deliberative Mapping workshops. 


\section{Technical feasibility}

A. "At some point, business as usual will start to become technically unfeasible as resources deplete, like far into the future so there is a risk" (Specialists group participant, on Business as usual).

B. "Carbon capture and storage, it just isn't there so it's not actually going to be possible for 20 or 30 years" (Activist citizens group participant, on carbon capture technology under Large-scale technologies and Local energy partnerships).

C. "Most of the technology that's needed to run a smart tech society is already in everybody's cell phone" (Deliberative citizens group participant, on Smart tech society).

D. "The school solar panel campaign is already being rolled out, home solar panels getting reduced tariff, it's already happening in varying scales" (Deliberative citizens group participant, on Local energy partnerships).

E. "A bit of a niche thing that is going to happen in a few places but probably not very relevant for others" (Grassroots innovator citizens group participant, on Off-grid energy communities).

\section{Carbon reduction}

F. "Best case scenario, utterly impossible, worst case scenario is even worse!" (Activist citizens group participant, on Business as usual)

G. "Effectiveness of carbon savings and the riskiness of it... sticking with business as usual is a very risky scenario" (Grassroots Innovator citizens group participants, on Business as usual).

H. "Same with capture and storage, it's not proven. Fusion... I'm not sure whether that's going to happen, so the downside for me is more whether in practice things these will come through to the scale that is needed" (Specialists group participant, on Large-scale technologies).

I. “There's more emphasis on energy efficiency which is important, I don't see this vision is necessarily at odds with meeting the carbon targets... it depends on what people prioritise" (Specialists group participant, on Deliberative energy society).

J. "smart tech and off-grid scored the two highest... [because they are] the only ones which say that energy is almost entirely supplied by renewable energy" (Specialists group participant, on Smart tech society and Off-grid energy communities).

\section{Environmental impacts}

K. "I think it's generally accepted that we're going in the wrong direction!" (Deliberative citizens group participant, on Business as usual).

L. If you get people on board and get them interested, then I think it brings on greater environmental possibilities [and] improvements because you get more understanding by a wider range of people" (Consumer citizens group participant, on Deliberative energy society).

M. "Pollution, land use, resource use and so the two lowest I've got there is large scale tech and smart tech and I score them very low because what I would call the fetishisation of carbon, so smartphones are not intrinsically great, they use an awful lot of resources and you can imagine an awful lot more tech actually going the same way." (Specialists group participant, on Large-scale technologies and Smart tech society).

N. "The actual environmental damage is going to be a lot less because you're not consuming as much are you?"... "And it's likely to take advantage of locally available energy sources"... "And those are more likely to be renewable" (Deliberative citizens group participants, on Local energy partnerships).

O. "Imagine if everyone lived off-grid and there was a rule, you can't burn anything, that should improve the environment, but it probably won't improve your life" (Consumer citizens group participant, on Off-grid communities).

\section{Economic efficacy}

P. "A lot of money, bills have been going up every year for the past 20 years, even though wholesale prices now are lower than they ever have been, electricity bills are not coming down" (Consumer citizens group participant, on Business as usual).

Q. "Large scale technology: there is an issue that is the current model actually going to fund it?" (Specialists group participant, on Large-scale technologies).

R. "It could be high because actually it could be a real enabler to make more efficient delivery of energy security and the smartness of the technology, the smartness of the system, it's actually improving it rather than disrupting it" (Specialists group participant, on smart tech society).

S. "I think it's pretty much guaranteed to be cost effective... because it's a community deciding what it's going to do and if it doesn't believe that there is a payback for the community then it won't do it" (Deliberative citizens group participant, on local energy partnerships).

\section{Political practicality}

T. "fusion and large-scale biofuels are, I feel are less credible, so more difficult to transition to those" (Specialists group participant, on Large-scale technologies).

U. "coming to a decision about moving to renewables maybe a bit difficult, there's lots of different opinions" (Deliberative citizens group participant, on Deliberative energy society).

V. "I think that in a good situation, the majority will take it on board and it will be very efficient but I think I was further down in the worse scenario... Because there will be people who don't understand the technology" (Consumer citizens group participant, on Smart tech society).

W. "You've got in theory a more democratic build up here because they're local, so you're negotiating, reaching decisions" (Deliberative citizens group participant, on Local energy partnerships).

X. "And off-grid, bonkers, people aren't going to stand for the level of quality or the cost to the energy at that level, you're losing out all the efficiencies and all the sharing that you would have that the existing system gives you" (Specialists group participant, on Off-grid energy communities). 


\section{Public acceptability}

Y. $\quad$ "Business as usual, it's not going to involve people, it's just going to be carried on with the companies making rules and nothing's going to change" (Consumer citizens group participant, on Business as usual).

Z. "It's unlikely to be in my back yard" (Grassroots innovator citizens group participant, on Large-scale technologies).

AA. "Obviously here... you've got members of the public that are active participants" (Specialists group participant, on Deliberative energy society).

BB. "[We] are going to have to try and find public buy-in but in terms of how important for me personally is public acceptability, I'd rather just get on with it regardless myself" (Grassroots innovator citizens group participant, on Deliberative energy society).

cC. "We've got the phones, we've got the computers, and this is just the next step isn't it? We're already there" (Deliberative citizens group participant, on Smart tech society).

DD. "It's a bit of a Marmite"... "It will be quite a big divide"... "But it's going to be a minority who do" (Deliberative citizens group participants, on Off-grid energy communities).

\section{Societal fairness}

EE. "I don't see climate targets being met so I see the damage costs of climate change being experienced and those not being equally experienced, those will hit the vulnerable in society the hardest" (Specialists group participant, on Business as usual).

FF. " '...you could see a scenario with that one where they can have very high prices and there's no regulation of that, it's not clear" (Specialists group participant, on Large-scale technologies).

GG. "I think it's quite fair, purely because I like the idea of the public being active members, partners in the decision making and I think that really could be fair in that sense" (Deliberative citizens group participant, on Deliberative energy society).

$\mathrm{HH}$. "I think this is the one for me of all of these options that is the most likely to result in a fair outcome because by definition, it's a community initiative, it's consensual, you get out of it what you put into it" (Deliberative citizens group participant, on Local energy partnerships).

II. “If people don't want to be off-grid and it's a negative development for them, then maybe it's not massively empowering"... "But that's wrong because we're not talking about the journey, we're talking about the end result" (Activist citizens group participants, on Off-grid energy communities).

\section{Table 2. Example quotations from Distributed Deliberative Mapping group appraisals of sociotechnical}

energy visions. Quotes are organised by the main appraisal criteria themes. For each quote the group affiliation of the participant(s) that made the statement, and the energy vision being referred to, are noted in parentheses. 


\begin{tabular}{|c|c|c|c|c|c|}
\hline Criteria & $\begin{array}{l}\text { Deliberative } \\
\text { citizens }\end{array}$ & Activist citizens & $\begin{array}{l}\text { Grassroots } \\
\text { innovator } \\
\text { citizens }\end{array}$ & $\begin{array}{l}\text { Consumer } \\
\text { citizens }\end{array}$ & Specialists \\
\hline $\begin{array}{l}\text { Technical } \\
\text { feasibility }\end{array}$ & $\begin{array}{l}\text { Feasibility }(\bar{x}= \\
16.7 \%)\end{array}$ & $\begin{array}{l}\text { Practical } \\
\text { timeliness }(\bar{x}= \\
14.3 \%)\end{array}$ & $\begin{array}{l}\text { Technical } \\
\text { achievability }(\bar{x}= \\
24.6 \%) ; \text { Speed of } \\
\text { delivery ( } \bar{x}= \\
22.7 \%)\end{array}$ & $\begin{array}{l}\text { Feasibility }(\bar{x}= \\
20.6 \%)\end{array}$ & $\begin{array}{l}\text { Technical } \\
\text { feasibility }(\bar{x}= \\
18.5 \%)\end{array}$ \\
\hline $\begin{array}{l}\text { Carbon } \\
\text { reduction }\end{array}$ & - & $\begin{array}{l}\text { Avoiding runaway } \\
\text { climate change }(\bar{x} \\
=14.3 \%)\end{array}$ & $\begin{array}{l}\text { Carbon saving } \\
\text { effectiveness }(\bar{x}= \\
24.6 \%)\end{array}$ & - & $\begin{array}{l}\text { Carbon reduction } \\
(\bar{x}=33.2 \%)\end{array}$ \\
\hline $\begin{array}{l}\text { Environmental } \\
\text { impacts }\end{array}$ & $\begin{array}{l}\text { Environmental } \\
\text { damage }(\bar{x}= \\
32.2 \%)\end{array}$ & - & $\begin{array}{l}\text { Risk reduction }(\bar{x} \\
=15.5 \%)\end{array}$ & $\begin{array}{l}\text { Environmental } \\
\text { quality }(\bar{x}= \\
21.3 \%)\end{array}$ & $\begin{array}{l}\text { Environmental } \\
\text { consequences }(\bar{x} \\
=27.3 \%)\end{array}$ \\
\hline $\begin{array}{l}\text { Economic } \\
\text { efficacy }\end{array}$ & $\begin{array}{l}\text { Cost } \\
\text { effectiveness }(\bar{x}= \\
18.9 \%)\end{array}$ & - & $\begin{array}{l}\text { Cost } \\
\text { effectiveness }(\bar{x}= \\
7.3 \%)\end{array}$ & $\begin{array}{l}\text { Cost } \\
\text { effectiveness }(\bar{x}= \\
21.3 \%)\end{array}$ & $\begin{array}{l}\text { Economic } \\
\text { feasibility }(\bar{x}= \\
18.9 \%)\end{array}$ \\
\hline $\begin{array}{l}\text { Political } \\
\text { practicality }\end{array}$ & $\begin{array}{l}\text { Efficacy of } \\
\text { governance }(\bar{x}= \\
10.0 \%)\end{array}$ & - & - & $\begin{array}{l}\text { Energy security ( } \bar{x} \\
=21.3 \%)\end{array}$ & $\begin{array}{l}\text { Societal } \\
\text { plausibility }(\bar{x}= \\
15.8 \%) ; \text { Vision } \\
\text { flexibility }(\bar{x}= \\
13.9 \%)\end{array}$ \\
\hline $\begin{array}{l}\text { Public } \\
\text { acceptability }\end{array}$ & $\begin{array}{l}\text { Social } \\
\text { acceptability }(\bar{x}= \\
7.9 \%)\end{array}$ & $\begin{array}{l}\text { Meaningfulness } \\
\text { of influence }(\bar{x}= \\
14.3 \%) ; \text { Progress } \\
\text { to an active } \\
\text { public }(\bar{x}=14.3 \%)\end{array}$ & $\begin{array}{l}\text { Public } \\
\text { acceptability }(\bar{x}= \\
5.5 \%)\end{array}$ & $\begin{array}{l}\text { Participation } \\
\text { increase }(\bar{x}= \\
15.6 \%)\end{array}$ & $\begin{array}{l}\text { Public } \\
\text { acceptability }(\bar{x}= \\
17.8 \%)\end{array}$ \\
\hline $\begin{array}{l}\text { Societal } \\
\text { fairness }\end{array}$ & $\begin{array}{l}\text { Fairness }(\bar{x}= \\
14.4 \%)\end{array}$ & $\begin{array}{l}\text { Progress to global } \\
\text { justice }(\bar{x}= \\
14.3 \%) ; \text { Fair } \\
\text { quality of life }(\bar{x}= \\
14.3 \%) ; \\
\text { Redistribution of } \\
\text { power }(\bar{x}=14.3 \%)\end{array}$ & - & - & $\begin{array}{l}\text { Equity of benefits } \\
(\bar{x}=27.4 \%)\end{array}$ \\
\hline
\end{tabular}

Table 3. Criteria to appraise alternative energy futures developed by the five DDM groups. Individual criteria produced by participants were grouped into criteria clusters based on qualitative analysis. In cases where a criterion overlapped with another criteria cluster, the aspect emphasised during the appraisals was used to categorise the criterion. Mean group weightings for each criteria cluster are given in parentheses, representing the relative importance assigned to each criteria cluster by each DDM group. 